\title{
As viagens de Saint-Exupéry pela América do Sul
}

\author{
The travels of Saint-Exupéry in South America
}

\author{
Claudia Musa Fay*
}

\begin{abstract}
Resumo: No final da década de 1920, aviadores franceses iniciaram voos experimentais ligando Paris ao Rio de Janeiro e Buenos Aires. No Brasil a companhia aérea Latécoère recebeu a licença em 1925 e em 1927 começou a utilizar semanalmente a rota Recife-Pelotas, com escalas em Maceió, Salvador, Caravelas, Vitória, Rio de Janeiro, Santos, Paranaguá, Florianópolis e Porto Alegre. Neste mesmo ano, a empresa teve o nome trocado para Aéropostale e foi a primeira a construir os campos de pouso chamados aeroplaces no litoral brasileiro. Seus pilotos se tornaram mitos, pois venciam desertos, atravessavam oceanos transportando correspondências sem atrasos. Os pilotos Mermoz e Saint-Exupéry, heróis da linha, destacaram-se também na literatura. Aviadores ou poetas, se tornaram-se inesquecíveis ambos perderam a vida voando. A presente comunicação procura através dos relatos literários das viagens, descrições de territórios desconhecidos, pois tal como "cavaleiros dos tempos modernos" por toda parte onde pousavam seus aviões eram admirados e acolhidos como amigos. Nossa proposta procura através do olhar do "outro", europeu da primeira metade do século, destacar o olhar desses viajantes.
\end{abstract}

Palavras-chave: Aviação. Literatura de viagem. Viajantes.

Abstract: In the late 1920s, French aviators began experimental flights linking Paris to Rio de Janeiro and Buenos Aires. In Brazil, the airline Latécoère received a license in 1925. In 1927, it began using a weekly route Recife-Pelotas, with stops in Maceió, Salvador, Caravelas, Vitória, Rio de Janeiro, Santos, Paranaguá, Porto Alegre and Florianópolis. That same year, the company's name was changed to Aéropostale and was the first to build airfields, called aéroplaces, on the Brazilian coast. Their pilots became myths because they have overcome deserts and crossed oceans carrying correspondence without delay. The pilots, heroes of the line, Mermoz and Saint-Exupéry have also stood out in Literature. Aviators or poets became unforgettable and they both lost their lives flying. This paper aims to research descriptions of unknown territories through reports of travel literature because like the "knights of modern times" everywhere they landed, their planes

* Doutora em História, Professora do Programa de Pós-graduação da PUCRS. 
were admired and welcomed as friends. Our proposal seeks through the eyes of "other", the European of the first half of the century, to highlight the look of these travelers.

Keywords: Aviation. Travel literature. Travelers.

"A terra ensina-nos mais a nosso respeito do que todos os livros. Porque nos resiste. O homem descobre-se quando se mede com o obstáculo."

(EXUPÉRY, 1995, p. 9)

Na primeira metade do século XX, a França ocupou os céus. $\mathrm{O}$ mundo recebia as noticias vindas de Paris e se admirava com os primeiros voos de Santos Dumont. Foi um período em que a fabricação e os testes se sucediam, tais como, a travessia do canal da Mancha, por Louis Blériot em 1909. Com o advento da Primeira Guerra Mundial a indústria artesanal se transformou e milhares de aviões foram produzidos entre 1914-1918.

No pós-guerra, mais especificamente, entre 1918 e 1933 alguns homens realizaram a incrível façanha de cruzar o oceano Atlântico ligando a Europa a América do Sul. Homens que desafiavam tudo a bordo de máquinas rudimentares submetidos a intempéries e a uma geografia selvagem e hostil. Aviadores e mecânicos, grande parte oriundos da guerra, motivados pela missão de transportar o Correio Aéreo, formaram a companhia aérea Aéropostale.

O presente artigo procura compreender através dos relatos literários de viagem os fatos, os gestos dos atores dessa epopeia. Procurar através do olhar do neste caso, Saint Exupéry, a visão de mundo, pois tal como analisou Sylvain Venayre, falar de viagem de aventura é falar dos que viveram estas aventuras:

A viagem de aventura pode ser vista como a necessidade de escapar do Velho Continente e, mais ainda, da civilização. A Europa é identificada como um polo repulsivo para aventura. O espaço, onde as aventuras ocorrem é um espaço afastado da civilização. (Venayre, 2002, p. 163).

Autores, tais como Jean Gérard Fleury, Joseph Kessel e, especialmente Saint Exupèry que foi piloto, um viajante de seu tempo 
que traz na sua narrativa a vivencia da sua profissão, transformaram em saga as viagens da Aéropostale ${ }^{1}$.

Nesta época houve um crescimento da população que vibrava com as aventuras, pois, para muitos era meio de escapar das dificuldades que assolavam a Europa. Os relatos das viagens de Saint Exupéry podem ser encontrados nas cartas que enviava regularmente para sua mãe, suas irmãs e seu cunhado, nas suas obras literárias e nas reportagens que escrevia para revistas. Reúnem as aventuras, as alegrias, as esperanças, as dificuldades físicas como as areias do deserto, e emocional, como a solidão no isolamento de uma cabine de avião.

Nos fala da beleza que vê do alto e das situações limite que enfrentava, tal como, a da queda de Guillaumet nos Andes e do seu esforço para encontrar seu companheiro com vida na imensidão da neve. Em seus 44 anos de vida Saint Exupéry sofreu muitos acidentes, criou rotas novas e morou em diferentes lugares como Cap Juby, Buenos Aires, Nova York, mas sempre retornando a Paris e ao sul da França. Fez viagens como jornalista a Moscou e a Espanha. Registrou suas viagens e aventuras nas passagens realizadas pela Guatemala, Argentina e Brasil.

A constância dos relatos enfocando paisagens era devido às referencias que os pilotos tinham com o solo para se orientarem. $\mathrm{O}$ desafio do transporte aéreo neste período era a competição com navios e trens que podiam viajar a noite. Portanto, as companhias de navegação aérea, a fim de se consolidarem, precisaram criar o serviço noturno. No livro Voo Noturno, Saint Exupéry, fala do perigo das rotas ao qual se acrescia o mistério da noite.

Na obra de Michel de Certeau temos que

Todo relato é um relato de viagem - uma prática do espaço. A este título, tem a ver com as táticas cotidianas, faz parte delas, desde o abecedário da indicação espacial ('dobre à direita', 'siga á esquerda'), esboço de um relato cuja sequencia é escrita pelos passos, até ao "noticiário' de cada dia ('Adivinhe quem eu encontrei na padaria?', ao 'jornal' televisionado ('Teherã: Khomeiny sempre mais isolado...'), aos contos lendários (as gatas borralheiras nas choupanas) e as histórias contadas (lembranças e romances de países estrangeiros ou de passados mais ou menos remotos). Essas aventuras narradas, que ao mesmo tempo produzem geografias

A Aeropostale marca o inicio da aviação comercial, em 1933 foi uma das formadoras da Air France. 
de ações e derivam para os lugares comuns de uma ordem, não constituem somente um 'suplemento' aos enunciados pedestres e as retóricas caminhatórias. Não se contentam em deslocá-los e transpô-los para o campo da linguagem. De fato, organizam as caminhadas. Fazem a viagem, antes ou enquanto os pés a executam. (Certeau, 1994, p. 200).

Portanto, para o autor o relato tem um papel decisivo. Ele tem como função fixar, ao mesmo tempo em que transforma lugares em espaços ou espaços em lugares.

Como André Gide, destaca no prefácio do livro Voo Noturno, "é com conhecimento de causa" que Saint-Exupery faz sua narrativa. Nestas circunstancias Gide, reconhece o valor literário das suas narrativas, bem como, as destaca como um documento que tem "sabor de autenticidade".

Antoine Marie Roger de Saint-Exupéry nasceu em 1900 em Lyon era filho do conde Jean de Saint Exupéry e de Marie de Fonscolombe, órfão aos quatro anos, passou a infância cercado por três irmãs e um irmão no castelo de Saint-Maurice-de-Remens, hoje transformado em museu, local de memória do poeta, escritor e aviador.

Primeiramente educado no colégio dos Jesuítas e logo após, interno na Suíça num colégio católico, dirigido pelos maristas entre (19151917). Seu sonho era ser oficial da marinha, mas ao ser reprovado no exame de admissão acabou optando pela aviação.

No final da Primeira Guerra Mundial, o engenheiro e industrial Pierre-Georges Latécoère, concebeu a extraordinária ideia de ligar por avião a Europa à América do Sul. Pensou em criar uma rede de malha aérea ligando $12000 \mathrm{~km}$, que sairia de sua base em Toulouse, passando pela Espanha, costa da Argélia, Marrocos continuando pela costa da África até o Senegal atravessando o Atlântico, fazendo uma ponte entre a África e a América do Sul. Assim, se abre a possibilidade de unir cidades europeias ao Rio de Janeiro, Buenos Aires e Santiago do Chile, desbravando paisagens grandiosas como o deserto do Saara, o Atlântico Sul e a Cordilheira dos Andes. Na época foi considerado louco, pois os rádios dos aviões eram limitados, os motores pouco confiáveis e os instrumentos de navegação eram a bussola e o compasso.

No entanto, menos de dez anos depois, o sonho de Latécoère tornava-se realidade. O voo Toulouse - Casablanca passou a ser uma rotina, porém, Casablanca-Dacar era mais complicado. Muitos pilotos já tinham já tinham sido feitos refém pelos mouros depois de um pouso forçado, motivado por quaisquer pane da aeronave. 
Antoine de Saint Exupéry ao ingressar em 1921 para o serviço militar alistou-se no Segundo Regimento de Aviação de Caça, sendo enviado para Estrasburgo a fim de iniciar seu treinamento como piloto. Em 9 de julho de 1921 fez seu primeiro vôo solo e conseguiu seu brevet (permissão para pilotar). Na ocasião recebeu uma proposta para aderir à Força Aérea, mas pressões familiares e da noiva Louise de Vilmorin fizeram com que fosse morar em Paris. Trabalhou como guarda-livros, caixeiro viajante e terminou rompendo o noivado e decidindo retomar sua carreira na aviação.

Ao ingressar na Aeropostale passou a pertencer ao grupo de pilotos cuja coragem desafiava os limites da razão. Logo foi nomeado diretor da Companhia Aeropostal Argentina. Durante os anos que lá viveu deixou-nos alguns escritos:

Tenho sempre diante dos olhos a imagem da minha primeira noite de voo na Argentina, uma noite escura em que cintilavam isoladas como estrelas, as raras luzes dispersas na planície. Cada uma assinalava, neste mar de trevas, o milagre de uma consciência. Neste lar, lia-se, refletia-se, encontrava-se em confidencias. Neste outro talvez, procurava-se sondar o espaço, alguém se consumia em cálculos sobre a nebulosa Andromeda. Ali amava-se. De longe em longe, brilhavam estas luzes no campo reclamando o seu alimento. Até as mais discretas, as do poeta, do mestre-escola, do carpinteiro. Mas, no meio destas estrelas vivas, quantas janelas fechadas, quantas estrelas apagadas. Quantos homens adormecidos [...]. (Exupéry, 1995, p.9).

Voar não era fácil. As suas narrativas estão impregnadas de um realismo que absorve o leitor, pois deixa à mostra a realidade em que a viagem era feita, pois, ao enfrentar as tempestades com aviões sem nenhuma cobertura, "era preciso inclinar-nos para lá do para-brisas para ver melhor, e as rajadas de vento silvavam durante muito tempo nos ouvidos" (Exupéry, 1995, p. 12).

A riqueza de detalhes nos relatos de viagem de Saint Exupéry propicia muitas inferências a respeito das condições adversas que os navegadores da época tinham que enfrentar:

E mesmo que a viagem chegue a bom termo, o piloto que navega seja por onde for, no seu troço de linha, assiste apenas a um espetáculo simples... A máquina, que ao principio parecia afasta-lo submete-o com cada vez mais rigor aos grandes problemas naturais. Sozinho no meio do imenso tribunal criado por um céu de tempestade, este piloto disputa o seu correio com três divindades elementares: a montanha, o mar e a tempestade. (Exupéry, 1995, p. 23). 
Nas correspondências (Exupéry, 1958, p. 116-117, 144) que enviava a família transparece a naturalidade com que tratava as distancias percorridas, pois tudo era minimizado, conforme carta endereçada à sua mãe: "Toulouse, 1926. Minha mãezinha, Parto pela madrugada para Dakar, sinto-me bem feliz. Levo o avião até Agadir e de lá continuo como passageiro. É uma viagenzinha de cinco mil quilômetros [...]".

Em outra carta mostra seu destemor em relação aos mouros, ao mesmo tempo em que, observa a atração destes pelas maquinas voadoras: "Dakar, 1926. Minha mãezinha. Eis-me em Dakar, todo feliz de viajar. Vi de perto mouros terriveis... Vestem-se de azul e tem uma grande cabeleira anelada. Um aspecto estranho! Vem a Juby, a Agadir e a Vila Cisneiros, para ver de perto os aviões. Ficam lá horas silenciosos".

$\mathrm{O}$ fascínio da paisagem vislumbrada por Saint Exupéry não poderia ficar guardada. Por sua natureza de desbravador tinha a necessidade de preservar e divulgar estas imagens. A máquina filmadora foi uma aliada para o registro das suas lembranças imateriais: "B Aires 1930. Minha mãezinha. Comprei uma pequena máquina de filmar para levar-lhe algumas lembranças das Américas. Estive ultimamente em Santiago do Chile. Que belo país e como a Cordilheira dos Andes é extraordinária! Encontrei-me lá a 500 metros de altitude, quando começava uma tempestade de neve. ... e lá em cima, no avião, uma sensação de solidão prodigiosa".

A importância da obra, dos feitos de Saint Exupéry e seus contemporâneos, foram imortalizadas nos escritos deste homem que dedicado à aviação e à literatura, tornou-se uma referencia mundial e que através dos seus registros trouxe até nossos dias o cotidiano da sua época.

Pilotando aviões, voou sobre os Andes e em 1931 publicou o romance Vôo Noturno, que logo se tornou um sucesso de vendas, ganhando na França o premio Femina que, mais tarde foi adaptado para o cinema. No mesmo ano se casou com uma viúva, Consuelo Goméz Castillo, o casamento, apesar das rupturas, ausências, ciúmes e infidelidades, durou por toda sua vida.

A empresa Aeropostale, começou a enfrentar problemas políticos, os quais fizeram com que a companhia deixasse de existir em 1933. Saint Exupery passou a ser piloto de teste e acabou ingressando na Air France, onde contribuiu para a divulgação e a publicidade da empresa. Em 1935 sofreu um acidente com um avião a serviço da Air France e precisou caminhar pelo deserto durante dois dias, sendo salvo por uma caravana. 
Durante este período foi encorajado pelo amigo Andre Gide a escrever sobre a profissão de piloto o que resultou na obra Terra dos Homens, publicado em 1939. Este livro vendeu cerca de três milhões de exemplares só na França. Tratava-se da historia de homens como Mermoz e Guillaumet, os pioneiros na travessia do Atlântico Sul e dos Andes respectivamente.

\section{Conclusão}

Resumidamente expôs-se um pouco dos feitos de Saint Exupéry que reuniu a pratica e a literatura, foi piloto e escritor. Seus livros fascinam, são lidos até nossos dias por milhões de pessoas, em diversas línguas, por crianças e adultos.

Suas viagens reúnem aventura e sacrifício. Nos fala das belezas do que vê do alto. E dos riscos que uma pane, uma queda, uma tempestade podem provocar. Nos fala de sobrevivência no deserto, enfrentando tribos hostis, também da sede provocada pelas longas caminhadas nas terras áridas, em busca de ajuda. Situações limites como a queda de amigos, a luta pela sobrevivência e a mensagem de que não devemos desistir nunca, o zelo e o esforço para salvar vidas.

Suas cartas, bilhetes, entrevistas revelam importantes indícios que se tornam fontes para pesquisas que buscam compreender tanto suas viagens pelo mundo, como aquelas que realizou ao interior de si mesmo. Seu legado é tão rico que possibilita novas interpretações por isso sua história pode sempre ser acrescida de um novo capitulo. A atualidade de seus pensamentos ultrapassou gerações e, tal como nos diz em sua obra que "Tu te tornas eternamente responsável pelo que cativas", toda a humanidade deve a ele o tributo pela sua existência.

\section{Referências}

CERTEAU, Michel. A invenção do cotidiano. 1. Artes de fazer. Petrópolis, RJ: Vozes, 1994.

CHADEAU, Emmanuel. Lê revê et la puissance l'avion et son siècle. Paris: Fayard, 1996.

CHADEAU, Emmanuel.Saint-Exupéry. Paris: Perrin, 2000.

CURTIS, Cate. Saint-Exupéry. Paris: Grasset, 2000.

SAINT-EXUPÉRY, Antoine. Cartas do pequeno príncipe. Belo Horizonte: Itatiaia, 1958. 
SAINT-EXUPÉRY, Antoine. Correio do Sul. Rio de Janeiro: Nova Fronteira, 1981.

SAINT-EXUPÉRY, Antoine. Terra dos homens. Lisboa: Europa-América, 1995.

SAINT-EXUPÉRY, Antoine. Voo Noturno, São Paulo: Difusão Europeia do Livro, 1983.

VENAYRE, Sylvain. La Gloire de l'aventure. Paris: Aubier, 2002.

Solicitado em 17/09/2012

Aprovado em 18/10/2012 